Volume: 3, Issue: 2, May 2018, Pages: 259-262, DOI: http://dx.doi.org/10.19082/ah259

\title{
BIO-MEDICAL AND BIO-PSYCHO-SOCIAL DISEASE MODELS ON THE MOVE TO HARMONIZATION
}

\author{
Wolfgang Seger ${ }^{1,2,3}$
}

1: Chairman of the Medical Advisory Board of the German Federal Rehabilitation Council, Frankfurt, Germany

2: Professor for Rehabilitation Medicine at the University of Bremen, Bremen, Germany

3: Former Medical Director and Deputy CEO of all Statutary Health and Long-Term-Care Insurances in Lower Saxony, Germany

\section{TYPE OF ARTICLE: SHORT REVIEW}

\begin{abstract}
Socio-political and economic health care decisions are often made on the basis of disease statistics alone. However, due to the changing panorama of diseases taking place in our century, especially healthcare of chronically diseased persons, it is often associated with impairing and cost-intensive, life-long concomitant personal and insurance-straining sequelae such as rehabilitation, psycho-social assistance, sick-benefits, invalidity pension or long-term care. These impacts must be considered simultaneously for appropriate decisions. In social welfare states, legislature is increasingly following the Bio-Psycho-Social Disease Model instead of the BioMedical Disease Model alone, aiming to achieve an inclusive society and putting into effect the Convention on the Rights of Persons with Disabilities. Therefore, the time has come to harmonize or merge the two underlying WHO classifications, ICD and ICF. This move to enrich the instrument box of public health statistics for political decision makers is overdue.
\end{abstract}

KEYWORDS: ICD, ICF, Disease Model, Social Medicine, WHO Classifications

\section{INTRODUCTION}

To face the challenges of the $21^{\text {st }}$ century it is necessary to enrich the instrument box of Public Health Statistics by joining or merging the Bio-Medical and the Bio-Psycho-Social Disease Models. The changing panorama of diseases which took place in the $20^{\text {th }}$ and present century is supporting the rediscovery of the social side of medicine and promoting an integrated care model. A rising life expectancy, an increasing age-induced disability and a more frequently occurring multimorbidity go along with the growing demand for an inclusive society and particular attention of the UN-Convention on Rights of Persons with Disabilities (1). Therefore experts of the WHO conclude that an integrated health information model would benefit medicine and health systems and would support the push for the implementation of a standard language-based electronic health record system towards better health services planning and reimbursement in the $21^{\text {st }}$ Century (2). To practice in the health system nowadays means to face paradigm shifts from presence to future, from the Bio-Medical Disease Model to the Bio-Psycho-Social Disease Model; a shift from acute to chronic and multimorbid; from treatment to prevention ; from cure to care; from hospital treatment to home treatment; from physician-led to self care and from ageing with a negative notion compared to people unaffected by disease to ageing with a strengthening of functional ability, intrinsic capacity and diversity in mankind.

\section{PREDOMINANT ORIENTATION OF STATISTICS TO THE BIO-MEDICAL DISEASE MODEL}

In social welfare states, we find several statutory agencies or insurances elaborating on the same patient at the same moment to tackle applications for benefits which they are responsible for. For example, a gainfully employed patient treated in a hospital after a car accident may be evaluated at the same moment by the social health insurance to cover the cost for acute hospital stay, by the private accident insurance to evaluate the causality of the accident and the need to compensate for the medical implications for the patient, by the Social Pension Insurance Fund to evaluate the need for a rehabilitation to avoid an invalidity pension and by the social unemployment insurance to evaluate the placement to the first working market.

\section{Correspondence:}

Professor Dr. Wolfgang Seger. Email: wolfgang.seger@mdkn.de and wolfgang.seger@hotmail.com Received: June 10, 2017, Accepted: April 25, 2018, Published: May 2018 iThenticate screening: April 25, 2018, English editing: May 05, 2018, Quality control: May 10, 2018

(C) 2018 The Authors. This is an open access article under the terms of the Creative Commons Attribution-NonCommercialNoDerivs License, which permits use and distribution in any medium, provided the original work is properly cited, the use is non-commercial and no modifications or adaptations are made. 
All these statutory and social insurances use statistics to evaluate their administrative functioning. But they still suffer from an orientation of their statistics to the Bio-Medical Disease Model calculating their costs on the basis of cost per disease, neglecting the costs for lost functioning and its compensation costs, each of them in a different way and only looking to the costs in their own jurisdiction. Functioning has not yet reached the data sheet of insurances' financing or policy makers' decisions though costs for the prevention or compensation of a loss of individual functioning may be many times higher than the costs for acute treatment of the underlying disease and will increase with the number of aged people.

\section{UPGRADE ICD WITH FUNCTIONING PROPERTIES}

If we match the Health Strategies like Promotion, Prevention, Treatment, Rehabilitation and Palliative Care to their main Impact Indicators like health, morbidity, mortality, recovery, disease control, functioning and quality of life, we must conclude that the use of ICD alone, which was well fitting into an environment of infectious diseases, is increasingly insufficient as a sole data base for health developments with the changing of the disease panorama. These major health strategies are to be serviced by both, ICF and ICD (3). Data strengthening must occur by mainstreaming these classifications interoperable at the individual program and health information system level. Consequently, the next question is whether the continuing use of two different classifications is adequate and helpful or we must ask if it isn't logical to discuss a merger or upgrade of ICD with functioning properties. This is the way the WHO is preferring. Interoperability, interaction, and linkages across classifications and systems are vital. Alex Ross, a director of the WHO stated in Tokyo in October 2016: "Valid and reliable data are essential for highquality health care systems. Supporting basic data collection such as civil registration and vital statistics (CRVS), as well as health and health care data, would help countries be better prepared for population ageing. In view of facilitating effective and efficient response to global population ageing, we acknowledge the value of using international statistical classifications including the International Statistical Classification of Diseases and Related Health Problems (ICD) and the International Classification of Functioning, Disability and Health (ICF) as well as a global survey on key indicators of health and needs of the elderly integrated into existing survey and routine reporting mechanisms as much as possible." (4)

\section{THE METHOD TO PROMOTE JOINT USE OF ICD AND ICF}

The WHO applied a 4-tiered strategy to identify the top health conditions that are associated with disability (5):

1) The first tier utilized the list of the top 100 conditions from the global burden of disease list from data sources at WHO found in the global Burden of Disease operations Manual. This document lists and ranks the health conditions based on „years lived with disability YLD“. It was initially reviewed by the workshop participants for relevance to rehabilitation, most prevalent in rehabilitation practice and amenable to rehabilitation interventions.

2) The second tier was aimed at identifying additional health conditions which did not appear in the original YLD list, but were expressed as rehabilitation-relevant and thus necessary to be included in the final list of health conditions

3) The third tier was to determine whether the identified health conditions were elements of compensation or provision of rehabilitation service, across a number of sample countries, (including Australia, Brazil, Germany and Turkey). This task was carried out with the aim of ensuring that there were no omissions of major rehabilitation-relevant health conditions, by examining cost coverage and country-specific provision of service.

4) The fourth tier involved identifying the Corresponding ICD codes and existing ICF Core Sets, if the latter are not existing, a conduction of a literature review followed matching with established ICF linking rules via ICF Research Branch to assign the functioning properties to ICD codes

\section{REASONS TO HARMONIZE ICD AND ICF}

Since the joint use of ICD and ICF has yet become an established practice in real-life contexts, an integration of functioning properties in the ICD revision process or a harmonization of ICD and ICF is desirable (6):

- to capture and provide the full (holistic) picture of health or health-related state of an individual

- to optimize the user value by enabling practitioners in determining the most relevant ICF categories for a particular ICD health condition

- to facilitate an integrated disease and operational model among systems from countries based on virtue of resource 
- to evaluate and record a comprehensive collection of data regarding a disease entity as wide-ranging and inclusive as possible

- $\quad$ to supply accurate and complete statistics classifying the complexity and cost of the care required

- to enhance the efficiency of casemix tools and better categorize the care needs and resource requirements of individual case types

- to utilize the standard and common language of the ICF on functioning in daily medical routine of in- and outpatient treatment

- to be helpful in interdisciplinary communication towards a concerted planning of care ultimately benefiting the patients.

\section{THE UPCOMING ICD-11}

The 2018 version of ICD-11 will be released for member state implementation. The goal is not to have a formal adoption, but to provide member states with a fully functioning robust classification that will allow Member States to plan for a transition in accordance with country priorities and capacities. Formal reporting of mortality data (and in the future morbidity data) based on the ICD-11 is expected to be implemented gradually by Member States post2018.

\section{PERSPECTIVES OF JOINT USE OF ICD AND ICF}

About 2500 years ago the well-known Chinese philosopher "Confucius", born 551 b.c., must have foreseen the coming of this challenge. He said: "If you want to alter public affairs, begin with the language". This dictum is constantly valid for structure and implementation of an integration of ICF and ICD in our times. Such a common language as a unified and standard classification would enable the user to record useful profiles of an individual's disease, functioning, disability and health in order to improve communication between different users, such as health care workers belonging to different professions, researchers, policy-makers and the public, including people with disabilities. An ICD upgraded with functioning properties as one meaningful guideline in our daily medical work gives us the chance to meet the present and future challenges of an already changing panorama of disease burden for the benefit of our patients. Using the Bio-Medical as well as the Bio-Psycho-Social Disease Model as an integrated Disease Model and document the medical and social findings by means of a harmonized or merged ICD and ICF is a promising tool for the medical profession to pick up the far-reaching change of the panorama of diseases, and of the societal awareness which has changed dramatically during the past decades. There is a lot of work to be done, let us roll up our sleeves. Our aged, chronic diseased, multimorbid and potentially disabled patients live in this exciting and dramatic societal, medical and social breakover, and we as medical doctors must question and rethink our own contribution and impact to these changes.

\section{ACKNOWLEDGMENTS:}

NA

\section{Funding:}

NA

\section{CONFLICT OF INTEREST:}

The author declare that he has no conflict of interests.

\section{REFERENCES:}

1) United Nations: Convention on the Rights of Persons with Disabilities. 2008: Available from: https:/www.un.org/development/desa/disabilities/convention-on-the-rights-of-persons-withdisabilities/convention-on-the-rights-of-persons-with-disabilities-2.html.

2) WHO: ICD-11 Revision Conference Report. Tokyo, Japan; 2016. Available from: http://who.int/classifications/network/meeting2016/ICD-11RevisionConferenceReportTokyo.pdf.

3) Cieza A. presentation of "Global policy, the need to improve data for rehabilitation". WHO FIC network annual meeting. Tokyo, Japan; 2016.

4) Ross A. presentation of "Future data needs and family of classifications: Aeing and Rehabilitation". The way forward. WHO FIC network annual meeting. Tokyo, Japan; 2016.

5) Kohler F, Selb M, Escorpizo R, Kostanjsek N, Stucki G, Riberto M. Towards the joint use of ICD and ICF: a call for contribution. J Rehabil Med. 2012; 44(10): 805-10. doi: 10.2340/16501977-1062. PMID: 22990383. 
6) Escorpizo R1, Kostanjsek N, Kennedy C, Nicol MM, Stucki G, Ustün TB. Harmonizing WHO`s International Classification of Diseases (ICD) and International Classification of Functioning, Disability and Health (ICF): importance and methods to link disease and functioning. BMC Public Health. 2013; 13 : 742. doi: 10.1186/1471-2458-13-742. PMID: 23938048, PMCID: PMC3765138. 